\title{
Dennis H. Robertson: Análise Real e Monetária do Ciclo Econômico na Tradição de Cambridge
}

\section{Dennis H. Robertson: Real and Monetary Analysis of Business Cycles in the Cambridge Tradition}

Sérgio Fornazier Meyrelles Filho ${ }^{\mathrm{a}}$ ib

Rogério Arthmar ${ }^{\mathrm{b}}$ (i)

\begin{abstract}
Resumo: O presente artigo resgata a contribuição de Dennis H. Robertson ao estudo dos ciclos econômicos. Após breve introdução, a segunda seção revisa as duas principais vertentes explicativas do fenômeno no início do século XX. Na seção seguinte, são delineados os aspectos gerais da análise robertsoniana sobre as flutuações econômicas com base em fatores reais, conforme sistematizados em sua obra inicial $A$ study of industrial fluctuation, de 1915. Após, sua abordagem sobre o papel da moeda e dos diferentes tipos de poupança no contexto dos ciclos é examinada. A integração entre as análises real e monetária, desenvolvida por Robertson em Banking policy and the price level, de 1926, é o objeto da quinta seção. Na penúltima seção, apresenta-se a crítica de Keynes aos conceitos de poupança forçada, de sobreinvestimento e do acelerador. $\mathrm{Na}$ conclusão, indicam-se os pontos de distanciamento teórico e práticos entre as visões de Robertson e Keynes sobre as flutuações econômicas.
\end{abstract}

Palavras-chave: Ciclos econômicos. Sobreinvestimento. Poupança. Moeda. Taxa de juros.

\begin{abstract}
This paper reviews the evolution of Robertson's theory of business cycles. After a brief introduction, the second section goes over the main currents of thought on the subject in the beginning of the twentieth century. Next, it outlines the general contents of Robertson's analysis of economic fluctuations based on real factors, as put forward in his initial work A study of industrial fluctuations (1915). The following section revisits his early studies on the role of money in this context, as well as his distinct concepts of savings within the framework of cyclical movements. The integration of real and monetary analysis, developed on Robertson's most well-known work, Banking policy and the price level (1926), is the object of the fifth section. In the sequence, comes Keynes's criticism of the concepts of forced saving, overinvestment and the accelerator. Finally, Keynes's and Robertson's divergences, on theoretical and practical grounds, over the nature of the business cycles are highlighted.
\end{abstract}

Keywords: Business cycles. Overinvestment. Savings. Moeda. Interest rate.

JEL Classification: B13; B22; B31.

a Universidade Federal de Goiás, Faculdade de Administração, Ciências Contábeis e Ciências Econômicas. Goiânia, Goiás, Brasil.

b Universidade Federal do Espírito Santo, Departamento de Economia. Vitória, Espírito Santo, Brasil. 


\section{1 lntrodução}

Referindo-se certa vez ao estudo das flutuações econômicas, Dennis H. Robertson observou ser esse o campo da análise econômica que mais lhe instigava e no qual, possivelmente, se situava sua contribuição mais expressiva. ${ }^{1}$ Com efeito, tal interesse já se mostrava evidente desde a época em que Robertson era estudante na Universidade de Cambridge, Reino Unido. Por volta de 1913, ele havia coletado considerável massa de estatísticas referentes ao comportamento histórico de diversos setores produtivos nos países industrializados. Seu intuito, em princípio, limitava-se a analisar criticamente as principais teorias do ciclo então existentes, contrapondo-as às evidências empíricas. Encorajado por Arthur C. Pigou, todavia, Robertson logo abandonaria a mera postura crítica, rumo a uma contribuição positiva ao entendimento das oscilações comerciais. O trabalho daí resultante constituiria sua fellowship dissertation, que, aprovada, daria origem ao seu primeiro livro, A study of industrial fluctuation (doravante Study), publicado em 1915 (ROBERTSON, 1948).

No que segue, confere-se especial atenção à relação dicotômica entre os aspectos reais e monetários nos diferentes momentos da análise robertsoniana dos ciclos dos negócios. O presente artigo inicia com uma revisão das duas principais correntes teóricas a respeito do tema no início do século XX, a saber, a marshalliana e a continental. A seguir, são delineados os aspectos estruturantes da teoria de Robertson sobre os ciclos econômicos, conforme sistematizados no Study. Na continuação, sua análise do papel da moeda e dos diferentes tipos de poupança nesse contexto é examinada com certo detalhe, complementada pela integração entre as análises real e monetária dos movimentos cíclicos levada a efeito por Robertson em Banking policy and the price level (doravante Banking policy, 1932). Finalmente, realiza-se uma contraposição da teoria de Robertson com as ideias de Keynes sobre os fatores de instabilidade econômica, especialmente no que se refere aos conceitos de poupança forçada, de sobreinvestimento e do acelerador. A conclusão ressalta os elementos teóricos e práticos de distanciamento entre Robertson e Keynes no tocante às flutuações da economia.

1 Dennis Holme Robertson (1890-1963) foi um dos mais importantes economistas britânicos da primeira metade do século XX, destacando-se particularmente nos anos de 1930 devido aos seus embates teóricos com John M. Keynes. Foi professor no Trinity College, na London School of Economics e, após a aposentadoria de Arthur C. Pigou, em 1943 sucedeu-o na cátedra de economia política em Cambridge até 1957 (DEUTSCHER, 1990, p. 59-61; FLETCHER, 2008, p. 213-234). Para os debates com Keynes, ver a segunda parte de Presley (1979). 


\section{A Teoria dos Ciclos Econômicos na Transição do Século XX}

Ao início do século XX, diversas explicações para os ciclos econômicos buscavam estabelecer fundamentação analítica mais sólida para a alternância regular entre períodos de prosperidade e depressão na economia internacional. ${ }^{2}$ Devido ao elevado grau de sofisticação do setor bancário e financeiro na Inglaterra alcançado ao longo do século anterior, as teorias dos ciclos comerciais elaboradas no âmbito da economia política britânica conferiam, de forma geral, proeminência aos movimentos especulativos e às variações correspondentes na demanda ou na oferta de moeda. De uma parte, a Lei de Say, tal como expressa por David Ricardo, Jean-Baptiste Say e James Mill, entre outros, ressaltando a correspondência unívoca entre poupança e investimento, se consolidou após as Guerras Napoleônicas como princípio explicativo maior da capacidade das economias de mercado operarem de forma estável no âmbito de uma acumulação progressiva de capital (KATES, 1998, p. 21-101; BAUMOL, 1977). De outra, a recorrência dos episódios de colapso econômico e financeiro nas economias industriais, todavia, renovava o desafio aos economistas partidários dessa linhagem teórica de elucidarem tal fenômeno em termos compatíveis com a Lei de Say. ${ }^{3}$

A resposta mais articulada da ortodoxia ao fenômeno das crises surgiu nos Principles of political economy, de John Stuart Mill (1965), em que os ciclos comerciais nasceriam não de falhas na demanda, mas da expectativa de eventos capazes de promover uma alta localizada de preços e fomentar, desse modo, uma ação especulativa de aprovisionamento de estoques por parte dos homens de negócios. A oferta adicional de crédito pelo sistema bancário acomodaria essa demanda extraordinária que, ao ampliar o poder de compra, produziria um avanço generalizado dos preços, induzindo outros indivíduos a se lançarem na corrente especulativa e reforçarem a busca por crédito. Algum tempo depois, porém, os comerciantes mais experientes, percebendo o afastamento excessivo dos preços em relação aos seus respectivos valores, passariam a se desfazer de seus estoques. Nesse momento, teria início a reversão do ciclo comercial, com restrição imediata do crédito, liquidação de preços e insolvência ampla (MILL, 1965, p. 733-751; FORGET, 1990).

Alfred Marshall, em The economics of industry (MARSHALL; MARSHALL, 1994, p. 119-127; 150-157) e, adiante, em Money credit and commerce (MARSHALL, 1923, p. 246-263; WOLFE, 1956), seguiria linha de raciocínio análoga, enfatizando, entretanto, a discrepância entre a taxa normal de juros, que vigoraria em condições de estabilidade econômica, e a taxa de desconto, definida pela po-

2 Ver Hansen (1964, p. 211-498), Haberler (1946, p. 5-254) e Mitchell (1913, p. 3-20).

3 Para uma descrição histórica dos episódios de crise bancária e sistêmica dos países industriais durante o século XIX (1815, 1825, 1847, 1857, 1866, 1873 e 1882) e que progressivamente adquiriram amplitude internacional, consultar Hyndman (1903, p. 17-162). 
lítica dos bancos e que poderia se distanciar da primeira. Assim, por exemplo, um ingresso extraordinário de ouro no país elevaria as reservas bancárias, facilitando a expansão do crédito por meio de juros mais atrativos e ocasionando elevação subsequente dos preços, a qual despertaria um movimento especulativo que logo envolveria a totalidade da economia. Quando a capacidade de expansão do crédito atingisse o seu limite, definido pelo total das reservas metálicas dos bancos, a taxa de juros efetiva sofreria majoração, restringindo os novos empréstimos e dando início à fase reversa do ciclo comercial, conformando um processo de caráter cumulativo. Como descrito pelo próprio Marshall:

Esses movimentos podem ser modestos, mas agem como uma pedra ro-
lando em uma montanha coberta de neve. A pedra cobre-se com um
pouco de neve, e a bola que se forma cresce ainda mais. Finalmente,
forma-se um grande movimento que, sob condições excepcionais, con-
verte-se numa avalanche. De modo análogo, uma pequena flutuação
no preço iniciada por poucas pessoas que se encontravam na margem
de dúvida e, portanto, suscetíveis a serem influenciadas por uma causa
qualquer, age sobre a opinião de outros e logo se amplifica. Caso o mer-
cado se encontre em situação nervosa ou histérica, mesmo uma causa
tão singela como uma módica elevação na taxa de desconto pode ini-
ciar uma avalanche na bolsa de valores, chegando até mesmo ao pânico
(MARSHALL, 1923, p. 259).

Assim como em outras áreas da economia, a originalidade de Marshall, particularmente no tocante ao caráter cumulativo da especulação aliada às variações do crédito, exerceria profunda influência nos desenvolvimentos analíticos ligados aos ciclos econômicos ao final do século XIX e início do XX. A abordagem teórica dominante em Cambridge nesse período assentava-se na identificação das falhas das economias de mercado com o intuito de divisar a melhor forma de mitigá-las e promover, assim, maior bem-estar econômico (BACKHOUSE; NISHIZAWA, 2010, p. 1-14). Do ponto de vista da economia agregada, isso significava, contrariamente às prescrições da Lei de Say, aceitar a possibilidade de divergência entre poupança e investimento como causa última das flutuações cíclicas e de seus desdobramentos. No âmbito da proposta marshalliana, porém, tal rompimento nasceria, de modo geral, da possibilidade inerente ao sistema bancário de estender ou restringir o crédito e, consequentemente, o poder aquisitivo em circulação, sem correspondência com a poupança efetiva dos agentes econômicos. Eventualmente, o desequilíbrio poderia envolver ainda rigidez nos salários e alterações na demanda por moeda (BIGG, 1990, p. 68-100; LAIDLER, 1999, p. 79-80; BRIDEL, 1987, p. 52-109).

O reflexo mais conspícuo dessa anomalia sistêmica localizava-se na diferença entre a taxa de juros natural, definida por fatores de ordem real da economia como as decisões de poupança e as oportunidades de investimento, e a taxa de desconto, resultante do arranjo institucional do sistema bancário e das decisões de 
seus administradores. Esse processo disjuntivo entre os campos real e monetário da economia seria potencializado pelo comportamento das expectativas referentes às decisões de investimento, colaborando para o seu distanciamento ainda maior da poupança real e desorganizando, portanto, os preços, a produção, o crédito e o volume de emprego. O remédio sugerido, em geral, envolvia o realinhamento mais rápido entre as duas taxas de juros por parte dos bancos, bem como maior transparência das informações econômicas visando atenuar a especulação. Com adaptações mais ou menos significativas, tal abordagem exerceria significativa influência nas explicações dos ciclos anteriores à Grande Depressão formuladas por Arthur C. Pigou, Frederick Lavington, John M. Keynes e, até mesmo, em certa medida, por Knut Wicksell e os economistas da escola de Estocolmo (LAIDLER, 1991, p. 89-152; PATINKIN, 1982, p. 36-57). Como assinalou Gottfried Haberler em sua síntese dos processos cumulativos associados à teoria dos ciclos de inspiração marshalliana até os anos de 1930:

Uma elevação na taxa de lucro (ou na taxa de juros de equilíbrio) apresenta-se simplesmente como um deslocamento para a direita da curva de demanda por novo dinheiro. Sob condições normais, a curva de oferta -devido a habilidade dos bancos em prover novo dinheiro e às outras forças inflacionárias atuantes na produção- é bastante elástica. O importante é que a curva de demanda por crédito não deve ser considerada relativamente fixa. Ao contrário, ela está sujeita a rápidos deslocamentos sob a influência de inúmeros fatores, como preços em alta, invenções e descobertas, ondas de otimismo ou pessimismo, queda nos custos de produção, mudanças na situação internacional do país, e assim por diante (HABERLER, 1936, p. 3).

Já a tradição continental dos ciclos econômicos seguiu caminho distinto daquele adotado pela corrente marshalliana na Inglaterra. Os teóricos subconsumistas da linhagem de Simonde de Sismondi, em seus Nouveaux principes d'economia politique (1817), Thomas R. Malthus, nos Principles of political economy (1820), e mesmo os populistas russos (narodniks) como Vasily Vorontsov (1847-1918), em The destiny of capitalism in Russia (1882), enfatizavam a incapacidade estrutural do capitalismo de gerar uma demanda doméstica de consumo - tanto por parte dos trabalhadores, quanto dos capitalistas - suficiente para absorver a totalidade de uma produção industrial em crescimento. A saída para a oferta excedente deveria ser encontrada, forçosamente, nos mercados externos. No caso dos países retardatários, tal deficiência poderia ainda comprometer o pleno desenvolvimento capitalista e, portanto, o advento futuro do socialismo (ARTHMAR, 2009; MILIOS; SOTIROPOULOS, 2007). A dificuldade analítica de tal leitura da realidade da época, contudo, residia no fato de que a constatação de uma insuficiência latente de demanda sob o capitalismo possuía como desdobramento lógico não uma tendência aos ciclos econômicos, mas, sim, à estagnação crônica da economia. 
Influenciado pelos estudos de Karl Marx em seus esquemas de reprodução no volume terceiro de $O$ Capital, o livro do economista ucraniano Mikhail Tugan-Baranovsky (1865-1919), intitulado Les crises industrielles en Anglaterre (1894), representou avanço significativo na teoria dos ciclos econômicos ao localizar o elemento dinâmico do processo não nas despesas de consumo, mas na fabricação de bens de capital. De uma parte, afirmou Tugan-Baranovsky, a pressão competitiva, aliada à falta de coordenação entre os capitalistas, geraria tendência à desproporção entre os setores da economia, desaguando em uma crise geral de superprodução. De outra, o capital livre, na forma de poupanças depositadas no sistema bancário e oriundas dos rendimentos fixos contratuais, seria represado durante certo tempo até que a pressão por sua aplicação produtiva deflagrasse uma onda de investimentos. A fase de prosperidade, concentrada na produção excessiva de capital fixo, duraria até o esgotamento dos fundos livres, quando então as taxas de juros sofreriam reajuste, já que o fluxo de poupança advindo do crescimento econômico resultaria lento e insuficiente para financiar os projetos em curso. A maturação dos investimentos, por sua vez, levaria a uma retração em sua demanda e consequente queda nos preços dos bens de capital, desajuste que logo englobaria os diversos setores da economia (TUGAN-BARANOVSKY, 1913, p. 186-279; BARNETT, 2001; HANSEN, 1964, p. 277-291). O processo cíclico foi comparado por Tugan-Baranovsky à operação de uma locomotiva, em que a pressão acumulada faz o pistão se mover ao longo do cilindro, retornando à sua posição de origem após a liberação da força expansiva.

Finalmente, o novo capital fixo é concluído. Tem-se novas fábricas, novas casas, novos navios, novas estradas de ferro. Em seguida, os novos empreendimentos se tornam mais raros. A demanda por todos os materiais que constituem os elementos do capital fixo sofre redução. A distribuição da produção deixa de ser proporcional; as máquinas, as ferramentas, o ferro, as telhas, as madeiras para construção, enfrentam demanda menor do que anteriormente, porquanto as novas oportunidades de investimento já não são mais tão numerosas (TUGAN-BARANOVSKY, 1913, p. 271).

Para os propósitos deste artigo, importa destacar igualmente o trabalho de Arthur A. C. Spiethoff (1873-1957), vinculado à escola histórica alemã e que, a partir das teses de Tugan-Baranovsky, desenvolveu a sua teoria dos ciclos em uma série de trabalhos publicados entre 1902 e 1909. ${ }^{4}$ Para Spiethoff, a fase de prosperidade teria início devido à perspectiva de maiores lucros, levando ao uso pleno da capacidade instalada. No estágio seguinte, novas fábricas e prédios seriam construídos de forma maciça, mobilizando materiais para a construção civil e a produ-

4 Quanto à explicação peculiar dos ciclos com base na hierarquia dos bens elaborada pelos economistas austríacos Ludwig von Mises e Friedrich Hayek, ver Laidler (1999, p. 27-50) e Hansen (1964, p. 384-393). 
ção de equipamentos. Após a sua conclusão, as novas fábricas passariam a descarregar no mercado uma oferta ampliada de bens de consumo final, atendendo a lacuna existente na demanda ou, até mesmo, ultrapassando-a. Nesse instante, face ao esgotamento das oportunidades de investimento, cairia a procura nos ramos produtivos de bens de capital em vista da inviabilidade econômica do emprego de novos capitais como estradas de ferro, usinas, maquinaria, meios de transporte etc. além daqueles agora em operação. Estabelecer-se-ia, assim, tanto a saturação de capital fixo quanto a superprodução geral. A fase expansiva, contudo, contrariamente ao previsto por Tugan-Baranovsky, seria deflagrada, na visão de Spiethoff, não por pressão do acúmulo de capitais livres, mas pelo empuxo fornecido aos investimentos por novas tecnologias, pela descoberta de territórios inexplorados e pela reposição do capital depreciado, até que o espaço de oportunidades para os investimentos estivesse suficientemente preenchido (DIEBOLT, 2007; HANSEN, 1964, p. 292-300; MITCHELL, 1913, p. 10-11).

Por fim, com base nas contribuições de Tugan-Baranovsky e Spiethoff, o economista francês Albert Aftalion (1874-1956), na obra Les crises périodiques de superproduction (AFTALION, 1913), contestou a autonomia dos ciclos com base exclusiva no comportamento de indústria de bens de capital, a qual, segundo ele, teria seus movimentos cíclicos ligados ao comportamento da demanda por bens de consumo, da mesma forma que um organismo vivo não poderia funcionar de maneira saudável se uma de suas partes adoecesse. O progresso econômico, conforme Aftalion, ocorreria de forma cíclica por obra de três fatores principais, a saber: a) o longo período de gestação dos bens de capital, cujo estoque portanto viria a se ajustar a um crescimento moderado da demanda por meio de saltos; b) a grande durabilidade do capital fixo, que exigiria tempo considerável durante a depressão até sua completa depreciação; e c) o princípio do acelerador, segundo o qual pequenas variações na demanda por bens de consumo induzem grandes variações na demanda por bens de capital (AFTALION, 1913, p. 219-405; HANSEN, 1964, p. 247-262). Nos termos do economista francês:

Durante a prosperidade, a elevação dos preços pressiona o aumento da produção. Mas essa oferta adicional não pode se materializar senão após a construção prévia das instalações necessárias. Como tal construção demora tempo demasiado, o atendimento insuficiente das necessidades e a alta dos preços incitam durante todo o tempo novos investimentos, nova fabricação de capitais fixos e, ademais, à sua fabricação em quantidades excessivas, numa palavra, a uma supercapitalização. Esse processo se evidencia em sua inteireza à medida que as construções se encontram em via de finalização. Nesse momento, a superprodução se revela. Os preços desabam. A crise se inicia (AFTALION, 1913, p. 401). 


\section{Robertson e o Study of Industrial Fluctuation}

A obra dos ciclos econômicos de Robertson pode ser considerada sob a perspectiva de uma releitura da tradição marshalliana sobre o tema, privilegiando, contudo, os fatores reais ressaltados pelos autores continentais (PRESLEY, 1979, p. 176-177). A instabilidade industrial, na ótica de Robertson, possuiria caráter eminentemente cíclico no sentido de que cada fase de expansão traria consigo, necessariamente, os elementos de sua reversão. Esses movimentos iniciais na produção e nos preços terminariam, a certa altura, transmitidos aos demais setores produtivos, resultando, assim, em oscilações concomitantes de toda a atividade econômica. Em tal perspectiva, as causas dos ciclos resultariam estritamente reais. Fatores monetários ou psicológicos seriam capazes de exacerbar os movimentos expansivos e agravar as depressões econômicas, revelando-se, porém, impotentes no sentido de gerarem, por si próprios, tais movimentos.

O Study inicia por uma investigação acerca das forças que encorajariam determinada indústria a modificar o seu nível de atividade. Partindo de uma análise microeconômica, Robertson supunha ser possível, em um segundo momento, explicar com maior propriedade os movimentos em nível agregado. Nesse contexto, um ramo particular da indústria poderia ser estimulado a expandir sua escala de produção sob três circunstâncias: a) devido a uma redução dos seus custos reais de produção; b) perante um aumento de sua procura pelos produtos de outras indústrias e, assim, do esforço que o setor específico estaria disposto a empreender, em termos da sua própria produção, para a aquisição desses produtos; e c) em razão do aumento do valor de troca do seu produto em relação aos demais, devido, sobretudo, a um acréscimo em sua demanda ou a uma maior abundância relativa dos demais artigos.

O estímulo ao incremento da produção em uma indústria localizada, contudo, não seria suficiente para promover o início de uma etapa de prosperidade econômica. Para tanto, um movimento de recuperação da atividade industrial agregada durante um ciclo regular, indicando o fim de uma fase depressiva, deveria ser gerado a partir da influência, isolada ou conjunta, de um número limitado de fatores, a saber: a) o avanço generalizado da produtividade física do esforço empreendido na indústria sob o estímulo da depressão; b) o aumento do valor de troca dos produtos industriais em relação aos produtos agrícolas devido ao advento de colheitas abundantes; e c) a elevação da utilidade marginal atribuída aos gastos com bens de capital, ou seja, aos investimentos, por obra da intensificação na demanda por bens de consumo (ROBERTSON, 1948, p. 125-164).

O fulcro da análise de Robertson sobre o ciclo econômico, inspirada na tradição continental descrita, jaz na ideia de que as crises industriais teriam origem em 
uma tendência ao sobreinvestimento durante as fases de expansão e associada ao longo período de gestação dos novos bens de capital. No início da fase de prosperidade, os preços dos bens de consumo tenderiam a se elevar, fazendo com que os respectivos produtores se sentissem estimulados a expandir os seus investimentos. Levaria tempo, entretanto, para que a nova capacidade produtiva estivesse concluída e viabilizasse a oferta adicional de tais mercadorias. Nesse intervalo, os produtores dos bens de consumo, estimulados pelas receitas em alta e agindo isoladamente, ou seja, ignorantes em relação ao comportamento de seus concorrentes, prosseguiriam com seus investimentos em volume crescente. Como desfecho desse processo desordenado, alcançar-se-ia um estado de sobreinvestimento na economia. Em outros termos, chegaria o momento em que os investimentos recém terminados traduzir-se-iam em uma oferta de bens de consumo além do acréscimo inicial na demanda, conduzindo, por conseguinte, a uma queda de seus respectivos preços. Desapontados com o resultado pecuniário de seu esforço, os produtores agora passariam a reduzir drasticamente os investimentos. As indústrias produtoras de bens de capital, diante desse quadro, entrariam em crise, que logo se alastraria por todo o sistema, iniciando, assim, a etapa de depressão. De acordo com Robertson:

Como cada novo investimento, uma vez realizado, será capaz de operar por considerável período, o aumento na utilidade dos novos bens de capital será geralmente, em qualquer caso, fenômeno temporário; um ponto será alcançado além do qual investimento adicional envolverá sacrifício desproporcional ao desfrute decorrente dos novos bens de consumo dele derivados. De fato, contudo, devido à pressão concorrencial, agravada pelo lapso de tempo que deve transcorrer antes que os novos instrumentos estejam em condições de produzir, o investimento provavelmente será conduzido além de tal ponto (ROBERTSON, 1948, p. 240).

Três outras importantes características imanentes à produção capitalista contribuiriam para intensificar as oscilações cíclicas. A primeira delas residiria na divisibilidade imperfeita dos instrumentos de produção. Na indústria moderna, de produção em larga escala, os bens de capital dificilmente seriam constituídos por pequenas unidades, isto é, as máquinas e equipamentos tenderiam a apresentar grandes dimensões. Dessa forma, o incremento da capacidade produtiva não poderia ocorrer de forma gradual, sendo, antes, realizado aos saltos. Em segundo lugar, uma vez revelado o excesso de investimento, os produtores não poderiam simplesmente fechar ou deixar ociosas partes de suas plantas produtivas, pois tal decisão implicaria pesados custos, para não mencionar a indesejável descontinuidade do processo produtivo. Por fim, a longevidade dos investimentos também contribuiria para o aprofundamento da crise, pois quanto maior a vida útil dos instrumentos de produção, maior o tempo requerido para sua depreciação e mais duradoura, portanto, a depressão (ROBERTSON, 1948, p. 32-41). 


\section{A Moeda, o Ciclo Econômico e os Tipos de Poupança}

No Study, Robertson desenvolveu uma teoria das flutuações econômicas em termos essencialmente não monetários e familiares à tradição de Tugan-Baranovsky, Spiethoff e Aftalion. Apenas no último capítulo do livro, os aspectos relacionados à existência de um sistema de crédito e de salários pecuniários foram brevemente considerados. Robertson notou então que, durante o período de prosperidade, eventual aumento no crédito, devido a um influxo de ouro ou simplesmente a um estado favorável de confiança por parte dos bancos, poderia estimular ainda mais o avanço da produção e a tendência ao sobreinvestimento (ROBERTSON, 1948, p. 211-216; 238-239). Após certo tempo, o acréscimo na oferta monetária tenderia a elevar o nível geral de preços, conforme prescrito pela Teoria Quantitativa da Moeda. O aumento dos preços em termos absolutos induziria cada produtor, porém, a interpretar equivocadamente tal movimento como um acréscimo no preço relativo de seu próprio produto, criando um incentivo adicional para a expansão dos seus negócios.

Por outro lado, uma vez considerada a relativa rigidez dos salários nominais, da taxa monetária de juros e das taxas de intermediação bancária, a elevação dos preços propiciaria aos produtores fontes adicionais de ganho, estimulando-os a produzir e a investir cada vez mais. Seguindo essa mesma lógica, Robertson afirmava que um recuo na oferta de crédito durante a fase depressiva do ciclo agravaria ainda mais o movimento de contração da atividade econômica (ROBERTSON, 1948, p. 217-228; 240-241). O encarecimento dos serviços bancários e a redução do nível geral de preços, aliados à relativa insensibilidade dos salários nominais e demais encargos em termos monetários, agiriam como fatores de desestímulo à produção e aos investimentos, aprofundando a depressão econômica.

Embora não demonstrasse estar propriamente preocupado com uma definição rigorosa do termo poupança, era evidente que Robertson acreditava no que se convencionou chamar de uma teoria da poupança real (BRIDEL, 1987, p. 79-83; PRESLEY, 1979, p. 92-96). Essa concepção identificava a poupança disponível para viabilizar os investimentos com um estoque previamente acumulado de bens de consumo necessário para suprir a comunidade enquanto uma proporção maior dos seus recursos estivesse comprometida com a produção adicional de bens de capital. Se esses recursos reais não fossem acumulados ex ante, resultaria fisicamente impossivel realizar os investimentos (ROBERTSON, 1948, p. 170-171).

Sofisticar essa análise seria o grande desafio de Robertson. Ele daria um importante passo nesse sentido com a publicação, em 1922, do livro intitulado Money, no qual reconhecia que o sistema bancário, por meio dos seus empréstimos, seria capaz de alterar efetivamente o volume de recursos reais 
disponíveis para investimento. Diante de uma elevada demanda por empréstimos, os bancos poderiam optar por expandir suas operações de crédito, mesmo não havendo uma contrapartida material, isto é, poupança real, para tais empréstimos. Assim, uma quantidade adicional de dinheiro fluiria para o mercado de bens, deparando-se com uma oferta momentaneamente limitada e entrando em disputa com o dinheiro já nas mãos do público. Os preços desses bens elevar-seiam e os indivíduos com rendimentos fixos, como os assalariados, por exemplo, seriam obrigados a se abster de uma parcela de seu consumo corrente. Surgiria, desse modo, um montante suplementar de poupança forçada que permitiria o acréscimo efetivo dos investimentos na economia. ${ }^{5}$ Nas palavras de Robertson:

Enquanto o banco está somente fazendo novos empréstimos à medida que os anteriores são pagos, tudo vai bem. Mas suponhamos que o nosso novo empréstimo foi realmente "o primeiro" no sentido que constituiu uma adição líquida aos empréstimos circulantes do banco. [...] É possível que os comerciantes enfrentem, durante certo tempo, o aumento da pressão para comprar, recorrendo aos estoques de mercadorias. Mas terão logo que aumentar seus preços a fim de que o limitado fluxo de mercadorias se distribua entre seus fregueses. Assim, por meio do aumento dos preços, o público é forçado a compartir [...] a renda real que, de outra forma, teria exclusivamente para si (ROBERTSON, 1960, p. 73-74).

No ano de 1926, em Banking policy, Robertson buscou analisar a natureza dinâmica da economia com base no lapso de tempo decorrido entre o início do processo produtivo e o momento em que a mercadoria acabada chega às mãos do seu usuário. A produção levaria tempo e não poderia, portanto, ser expandida ou contraída de forma instantânea (ROBERTSON, 1932, p. 43). Segundo a definição de Robertson, um indivíduo estaria "privando-se" ou "poupando", isto é, realizando lacking, se durante dado período consumisse menos do que o valor do seu produto corrente. Caso contrário, haveria poupança negativa, ou dis-lacking. Em Banking policy, podemos identificar a existência de três tipos diferentes de capital: o fixo, o circulante e o imaginário. A cada um deles corresponderia um tipo distinto de poupança. O capital fixo consistiria no estoque de instrumentos de produção disponível à economia em determinado momento. Sua provisão seria garantida a partir de uma modalidade de financiamento denominada por Robertson de "poupança de longo prazo" (long lacking). O capital fixo, assim definido, corresponderia aproximadamente àquilo que Marshall havia denominado de capital especializado. ${ }^{6} \mathrm{O}$ capital circulante, por sua vez, seria constituído por um conjunto

5 A noção de poupança ou frugalidade forçada era bem conhecida dos economistas clássicos e neoclássicos como Henry Thornton, Jeremy Bentham, David Ricardo, Thomas R. Malthus, John S. Mill, Léon M. E. Walras e Knut Wicksell, entre outros (HAYEK, 1932).

"Sempre que o capital tenha sido concebido para uso em determinado negócio existe certa dificuldade em transferi-lo para outro; se a dificuldade é muito grande, o capital é dito especializado; caso contrário, ele é não-especializado" (MARSHALL; MARSHALL, 1994, p. 20). 
de bens de consumo e matérias-primas, nos mais diversos estágios de produção, que permitiriam ao processo produtivo ser levado adiante. Já o capital imaginário compreenderia um estoque de títulos, sem contrapartida em ativos reais, que representaria "[...] a riqueza imaterial conferida pela segurança ou prestígio nacional [...]" (ROBERTSON, 1932, p. 45). A existência desse capital dependeria da oferta de "poupança improdutiva" (unproductive lacking), que teria origem, sobretudo, em transferências de poder de compra do setor privado para o setor público.

Qual seria, contudo, para Robertson, a conexão entre a retenção de saldos monetários e a acumulação de capital? Suponhamos que determinado grupo de pessoas em uma comunidade, de posse do seu produto corrente, decidisse consumir fração menor desses recursos, ao contrário dos períodos anteriores. Por definição, esses indivíduos estariam privando-se de consumir ou, ainda, poupando. Como então poderiam utilizar os recursos poupados? Uma primeira alternativa consistiria em empregar tais fundos na compra de instrumentos de produção, ou no pagamento de trabalhadores produtivos. A segunda opção seria permitir a outrem, mediante empréstimos, utilizar os recursos de forma produtiva. Restaria ainda, todavia, uma terceira alternativa. As pessoas poderiam simplesmente conservar os recursos poupados sob a forma de moeda. Nesse caso, supondo tudo o mais constante, a acumulação de saldos monetários (entesouramento ou hoarding) ocasionaria uma redução da quantidade de dinheiro em circulação ativa. Em virtude disso, os preços cairiam e outros segmentos da comunidade poderiam, assim, expandir o seu consumo na mesma proporção em que os indivíduos em questão houvessem reduzido os seus gastos. Desse modo, em vez de uma poupança direcionada à provisão de capital, haveria ocorrido, então, o que Robertson denominava de "poupança abortiva" (abortive lacking).

Robertson, em Banking policy, com a colaboração de Keynes, elabora uma das mais complexas classificações dos diversos tipos de poupança da história da análise econômica. O termo "poupança espontânea" (spontaneous lacking) identificaria aquilo normalmente compreendido por poupança no sentido marshalliano, isto é, a parcela dos rendimentos de um indivíduo que voluntariamente opta por não consumir em determinado período e cuja magnitude dependeria, basicamente, do nível de sua renda corrente e do valor da taxa de juros, configurando um ato espontâneo de poupança. ${ }^{7}$ Ao contrário, se o indivíduo consumisse deliberadamente mais do que o total dos seus recursos correntes, haveria despoupança espontânea (spontaneous dis-lacking).

$7 \quad$ Marshall, nos Principles of economics (1890), concebia a poupança como um ato de deferimento do consumo presente por maior consumo futuro. O desejo de poupar teria como pré-condição a segurança do desfrute futuro do esforço corrente. O poder de poupar, por sua vez, dependeria do excesso de renda além das necessidades básicas, assim como do nível da taxa de juros. O motivo mais importante de poupança, contudo, residiria no desejo de melhorar a condição da família e dos descendentes (MARSHALL, 1920 p. 220-237). 
Obviamente, a mesma lógica seria aplicada no plano agregado, ou seja, em termos da economia como um todo. Robertson, porém, adverte que se, por um lado seria correto afirmar que em uma situação de equilíbrio monetário o volume total de poupança disponível para fins de acumulação coincidiria com a poupança espontânea (spontaneous lacking), por outro a mesma afirmação não poderia ser sustentada em uma situação de desequilíbrio, quando os fluxos monetários estivessem sujeitos a flutuações. Nesse caso, seria necessário considerar não somente a poupança espontânea, mas também a poupança forçada, a qual apresentar-se-ia agora em duas formas distintas.

A primeira delas, denominada por Robertson de "poupança automática" (automatic lacking), teria lugar quando um aumento no montante de dinheiro direcionado ao mercado de bens reduzisse o consumo efetivo de determinados grupos (ROBERTSON, 1932, p. 47). Essa procura adicional poderia ter origem na decisão de parte dos indivíduos de reduzir os seus estoques de moeda, levando a cabo um "desentesouramento" (dis-hoarding) ou, ainda, na criação de dinheiro novo por meio do sistema de crédito. Nas duas situações, o poder de compra adicional provocaria aumento de preços e garantiria aos seus detentores o acesso a uma parcela da produção que, caso contrário, seria consumida por outros indivíduos. Estes últimos, ainda que involuntariamente, proveriam a sociedade com uma disponibilidade adicional de recursos reais, denominada por Robertson de poupança automática (BRIDEL, 1987, p. 112; PRESLEY, 1979, p. 106).

Pode-se perceber que o conceito de poupança automática se aproximava consideravelmente da definição de poupança forçada utilizada em Money, com a adição de que tal fenômeno poderia decorrer igualmente de uma decisão quanto ao nível de entesouramento monetário. Em Banking policy, porém, existe ainda outro tipo de poupança forçada, denominado "induzida". Considere-se que, devido a um aumento na quantidade de moeda direcionada ao mercado de bens, o nível de preços tenha se elevado e um determinado grupo de indivíduos se veja submetido a um processo de poupança automática. Nesse caso, o valor real dos seus encaixes monetários teria caído a um nível inferior àquele considerado por eles como apropriado. Esses indivíduos procurariam, agora, recompor o nível ótimo dos seus balanços monetários retirando moeda de circulação por meio da redução do seu consumo. Na medida em que eles estivessem, dessa forma, consumindo menos do que a sua renda corrente, teria lugar, então, um processo de poupança induzida:

A poupança induzida ocorre quando o mesmo processo que impõe poupança automática sobre certas pessoas ao reduzir o valor real de seus encaixes monetários, faz com que elas mantenham dinheiro fora do mercado, abstendo-se de consumir o valor integral de seu produto corrente a fim de trazer o valor real de seu encaixe monetário novamente ao nível por elas julgado apropriado (ROBERTSON, 1932, p. 49). 
Como destacado por Robertson, as variações na poupança qualificadas como induzidas seriam diferentes daquelas ditas automáticas por se originarem em ação deliberada dos agentes econômicos visando modificar o seu consumo; ambas, todavia, resultariam de um mesmo processo, qual seja, alterações na quantidade de dinheiro direcionada ao mercado de bens. Nesse sentido, tanto a poupança quanto a despoupança de um ou de outro tipo poderiam ser entendidas como sendo de natureza compulsória e, juntas, conformando, respectivamente, o que se poderia designar de poupança ou despoupança "imposta" (imposed lacking ou dis-lacking). Como explicado por Robertson: "Para fins práticos, é conveniente agrupar em um só conjunto a poupança automática e a induzida, designando-as por poupança imposta" (ROBERTSON, 1932, p. 49). ${ }^{8}$

\section{A Sintese entre Fatores Monetários e Reais: Moeda, Poupança Forçada e o Ciclo Econômico}

Passando-se à análise dos ciclos econômicos formulada em Banking policy, admita-se a existência de uma situação inicial de equilíbrio entre a oferta e a demanda por poupança de curto prazo. Imagine-se, então, que um evento qualquer, repentinamente, provoque acentuado aumento na procura por capital circulante. Segundo Robertson, a oferta voluntária de poupança de curto prazo, por definição, não seria suficientemente elástica para fazer frente a deslocamentos de tal natureza. Nesse caso, a incumbência de satisfazer a expansão na demanda recairia, quase inteiramente, sobre os bancos. Esses últimos, diante da pressão dos empresários desejosos por aumentar o seu capital circulante, expandiriam os seus empréstimos além do nível justificado por eventuais entesouramentos que viessem a surgir, os quais o próprio Robertson considerava como pouco relevantes nessas circunstâncias.

Os novos empréstimos permitiriam aos empresários exercerem poder de compra adicional e levariam à contratação de novos trabalhadores, inclusive nas indústrias produtoras de capital circulante, estimuladas pelo aumento da demanda. A esses trabalhadores seria pago um determinado salário e a eles caberia, com isso, a capacidade de exercer poder de compra. Isso tudo traduzir-se-ia em maior montante de dinheiro direcionado ao mercado de bens de consumo. A produção desses bens, no entanto, não poderia ser expandida instantaneamente. Aconteceria, portanto, maior competição pela oferta disponível e, em consequência, os preços seriam majorados. Certos indivíduos passariam a consumir menos do que pretendiam inicialmente, especialmente aqueles cujos rendimentos monetários

8 É interessante notar que, conforme Robertson, o conceito de poupança induzida lhe havia sido sugerido por seu mais estreito colaborador à época, isto é, o próprio Keynes. Nesse sentido, observou: "A ideia de poupança induzida pertence ao Sr. Keynes" (ROBERTSON, 1932, p. 50). 
não se mostrassem capazes de acompanhar a marcha dos preços, sobretudo os assalariados e rentistas. Em virtude dessa incapacidade, eles experimentariam a redução de sua renda real e, dessa forma, ver-se-iam obrigados a reduzir o seu consumo, estando submetidos, então, a um processo de poupança automática. Além disso, a elevação do nível de preços reduziria também o valor real de seus encaixes monetários. Buscando recompô-los, os indivíduos retirariam moeda de circulação, reduzindo mais ainda o seu consumo e gerando, por conseguinte, poupança imposta adicional que, como visto, conformaria a poupança induzida de Robertson.

Como então a conjunção de tais eventos atuaria no correr do ciclo econômico? Partindo-se de um estado recessivo, admita-se que as indústrias produtoras de instrumentos de produção busquem expandir subitamente a sua oferta devido a um aquecimento na demanda por esses bens. Considera-se, por exemplo, que em resposta a uma invenção qualquer, a utilidade marginal estimada para o capital fixo tenha se elevado e, dessa forma, também a procura por instrumentos de produção. A fase ascendente do ciclo seria assim iniciada, caracterizando-se por um movimento quase rítmico de expansão da atividade econômica, movido pelas indústrias produtoras de capital fixo. Qual o papel da poupança forçada nesse processo?

Embora a poupança imposta pudesse financiar parte da nova demanda por capital durante a expansão, uma série de outros fatores faria com que a procura por capital circulante se tornasse cada vez maior, obrigando os bancos a expandir sempre mais os seus empréstimos (ROBERTSON, 1932, p. 72-76; 91-94). Dentre esses fatores, mereceriam destaque: a) o aumento progressivo do período médio de produção devido aos obstáculos físicos naturais e à especulação dos comerciantes, os quais, diante dos aumentos de preços, desejariam reter por mais tempo as suas mercadorias antes de colocá-las à venda; b) o fato de que os novos instrumentos de produção implicariam necessidade de capital circulante adicional não apenas durante o seu período de gestação, mas, também, ao longo de sua posterior operação.

Assim, à medida que se expandisse a produção de bens de capital, verificar-se-ia uma necessidade cada vez maior de poupança de curto prazo para mantê-los em funcionamento. Caberia aos bancos, nesse contexto, promover expansão progressiva do crédito e, por consequência, dos preços, de forma a gerar volumes cada vez maiores de poupança forçada. No entanto, não seriam apenas os novos empréstimos que contribuiriam nesse processo, pois certos agentes, sobretudo os empresários, diante da escalada dos preços, tenderiam a reduzir seus encaixes monetários (dis-hoarding) de forma a antecipar suas compras de mercadorias e obter ganhos especulativos. Nesse caso, a inflação seria estimulada ainda mais e, com ela, o processo de poupança forçada. 
Nem tudo no ciclo econômico, porém, estaria resumido à demanda e oferta de poupança de curto prazo, pois a expansão do capital fixo da economia somente seria possível caso houvesse provisão adequada da poupança de longo prazo. Como expresso por Robertson:

Até o ponto em quer alcançam as mãos de seus compradores finais, os bens de consumo e, da mesma forma, os instrumentos produtivos, requerem provisão de poupança [lacking] à qual dão origem. A poupança, aqui, é da variedade de curto prazo. [...] A aquisição de um navio, contudo, envolve provisão adicional de poupança, dessa vez da variedade de longa duração e por um período indeterminado, à qual a disponibilidade de mera porção de carne não é suficiente (ROBERTSON, 1932, p. 85).

De acordo com Robertson, a provisão da poupança de longo prazo seria garantida, principalmente, por meio de poupança espontânea adicional proveniente de três fontes, a saber: a) pelo reinvestimento de lucros por parte dos empresários; b) pela aplicação de lucros retidos por dirigentes de firmas de capital aberto; e c) mediante a aquisição de novas ações por agentes privados (ROBERTSON, 1932, p. 86). Fontes adicionais de financiamento poderiam advir, ainda, da redução dos encaixes monetários, o que, por seu turno, representaria um aumento na velocidade de circulação da moeda. Nesse caso, ocorreriam reajustes nos preços, localizados, inicialmente, no mercado de bens de capital fixo, mas que se estenderiam progressivamente a todos os demais setores da economia. Com isso, as pessoas com rendas fixas seriam submetidas, analogamente, a uma poupança compulsória. Percebe-se, assim, que, no esquema analítico proposto por Robertson em Banking policy, se por um lado a poupança forçada estaria primordialmente vinculada à provisão do capital circulante, por outro seria um equívoco ignorar sua ligação com a expansão do capital fixo durante a fase ascendente do ciclo.

Nesse ponto, apresenta-se a seguinte questão: qual, segundo Robertson, resultaria a política monetária mais sensata diante da existência da poupança forçada durante o ciclo? De acordo com sua análise, seria aquela condizente não com a estabilidade permanente dos preços, mas com a adequada expansão dos empréstimos bancários no sentido de gerar poupança forçada suficiente para possibilitar o aumento do nível de atividade justificado pelas condições subjacentes de utilidade ou custo (appropriate fluctuations). Ou seja, a política monetária deveria viabilizar os investimentos de caráter eminentemente real, inibindo, todavia, flutuações injustificadas ou irracionais baseadas em fatores puramente monetários ou psicológicos (innapropriate fluctuations).

A flutuação inevitável ou "apropriada", no léxico peculiar de Robertson, teria natureza eminentemente real e poderia estar restrita a alguns setores da economia, como no caso de uma inovação específica, ou assumir latitude mais ampla, como durante as fases sucessivas do ciclo. Após certo tempo, já na depressão, 
tanto os ganhos na produtividade do trabalho quanto na reorganização geral da produção causariam expansão na oferta, enquanto, nos estágios finais do boom, o uso intensivo da mão de obra e a administração leniente reduziriam o ritmo de crescimento de produto. Além disso, inovações de largo espectro, como as ferrovias, a energia elétrica e o motor a diesel tenderiam a intensificar o desejo de investir em tais equipamentos até o ponto de saturação temporária ser atingido. Outras forças em operação causadoras de oscilações inevitáveis na oferta compreenderiam a volatilidade das colheitas agrícolas e a queda de preço nos materiais de construção (ROBERTSON, 1932, p. 6-18). ${ }^{9}$

Em contrapartida, as flutuações "inapropriadas" ou evitáveis tenderiam a amplificar as variações reais do produto, inscrevendo-se aí a indivisibilidade de alguns tipos de equipamento, que exigiriam grandes saltos na capacidade produtiva além do recomendável pelo crescimento efetivo da demanda, em uma espécie de efeito acelerador. Adicionalmente, a pressão competitiva para atender a uma procura mais intensa poderia induzir cada firma a expandir o seu volume de produção sem qualquer informação sobre iniciativa similar de seus rivais, de modo que esses esforços desordenados terminariam por fazer a oferta final extravasar o montante rentável garantido pelo mercado. Simultaneamente, a influência psicológica mútua entre os industriais aceleraria a rápida difusão dos volúveis estados mentais sobre a saúde geral dos negócios, criando, assim, ondas sucessivas de confiança e de descrédito na economia. Finalmente, os produtores poderiam superestimar a magnitude da expansão na demanda anunciada por um aumento no seu preço de venda se não prestassem atenção devida à alta paralela nos custos, o que tenderia a induzi-los a aceitar uma escala de produção maior do que a apropriada (ROBERTSON, 1932, p. 34-39).

Seja como for, chegaria inevitavelmente o momento em que o processo de expansão daria lugar à crise. Em Banking policy, Robertson afirmava que ela poderia ter início caso o sistema bancário não se mostrasse capaz de promover o montante de poupança forçada necessário durante a fase de expansão. Esse tipo de crise, contudo, dizia ele, constituiria antes a exceção do que a regra, e uma deficiência de poupança de tal ordem seria capaz apenas de antecipar algo inexorável, ou seja, o momento em que o crescente custo dos instrumentos de produção

9 Em um artigo de 1934, intitulado "Industrial fluctuation and the natural rate of interest", Robertson, seguindo a argumentação mencionada, adverte que a taxa natural ou de equilíbrio marshalliana teria natureza volátil ao longo do ciclo pela circunstância de as inovações ou a descoberta de novos territórios deslocarem a curva de produtividade do investimento para a direita, enquanto o sobreinvestimento posterior implicaria em queda subsequente na mesma curva. Além disso, as mudanças na distribuição de renda em favor dos empresários devido à inflação de crédito moveriam a curva de poupança voluntária para a direita, enquanto os reajustes salariais subsequentes teriam efeito oposto. A consequência das flutuações na taxa de juros virtual ou "quase natural" ao longo do ciclo residiria na dificuldade de utilizá-la como norma para a política de juros bancários (ROBERTSON, 1934). 
e o declínio de sua respectiva utilidade marginal conduziriam os investidores a uma reavaliação das vantagens associadas à consecução de novos projetos. Assim, verificar-se-ia uma redução acentuada na demanda por bens de capital, processo que ocorreria independentemente da existência de uma oferta abundante de poupança, fosse espontânea ou forçada. Na descrição do próprio Robertson:

A crise pode ter lugar em um momento ditado pelo estado de pressão sobre o sistema bancário, em vez de pelo estágio alcançado no ciclo efetivo de construção. Ela pode ocorrer, dito de outra forma, antes do momento no qual o aumento nos custos dos instrumentos produtivos, ou mesmo o declínio em sua atratividade ocasionado por sua quantidade crescente, ainda que uma oferta de poupança de longo prazo [long lacking] esteja disponível, recomende a reavaliação da vantagem líquida de se adquirir novos instrumentos e o consequente declínio em sua quantidade demandada (ROBERTSON, 1932, p. 90).

Confrontadas com uma queda abrupta nas vendas de seus produtos, as indústrias produtoras de capital fixo entrariam em crise, a qual logo se estenderia por toda a indústria, conduzindo a economia rumo à fase descendente do ciclo, caracterizada por uma contração quase rítmica da atividade econômica. A partir daí todo o processo descrito em relação à fase de expansão sucederia em sentido inverso. O ritmo de acumulação de capital (fixo e circulante) seria drasticamente reduzido e a oferta voluntária de poupança tenderia a superar e a se tornar cada vez maior que a procura respectiva. Os bancos, em tais circunstâncias, reduziriam os seus empréstimos e, com isso, os preços cairiam ainda mais. Os mesmos indivíduos, antes punidos pela inflação, passariam agora a consumir mais do que haviam inicialmente planejado, ocorrendo um processo de despoupança forçada (savings running to waste). ${ }^{10}$ A economia permaneceria em depressão até o momento em que fatores reais, por exemplo, safras agrícolas abundantes ou alguma inovação de amplo alcance, estimulassem uma nova fase de prosperidade.

\section{Keynes e a Teoria dos Ciclos Econômicos}

Durante os anos de 1930, Keynes afastou-se progressivamente das concepções de Robertson, apesar de ter mantido constante correspondência com ele sobre o conteúdo do Treatise on money (1930) e dos esboços da Teoria geral. ${ }^{11}$ Em suas cartas anteriores à Teoria geral, Robertson já mostrava dificuldades em apre-

10 A ideia já havia sido antecipada por Pigou em Economics of welfare (1920) ao criticar a tese de Tugan-Baranovsky de que a poupança seria acumulada em grande volume antes de se viabilizar a retomada dos investimentos. "O que eles fizeram ao não despender seu dinheiro foi reduzir os preços em geral abaixo do nível que, de outra maneira, teria vigorado, permitindo a outras pessoas adquirir maior quantidade de bens" (PIGOU, 1920, p. 812).

11 Para a relação completa das cartas entre ambos, consultar Moggridge (1973, p. 523-524). 
ender a nova linha de pensamento de Keynes, insistindo na validade dos conceitos de privação (lacking) e entesouramento (hoarding), bem como nos seus respectivos efeitos sobre o ciclo econômico. A ruptura entre ambos ficaria evidente quando Robertson mostrou-se disposto a defender a tradição marshalliana, progressivamente descartada por Keynes em seu caminho para Teoria geral e associada por este último à antiga economia clássica ricardiana. Sobre isso, escreveu Robertson:

Não me agrada em nada seu tratamento do que você chama de economia clássica e eu denomino economistas modernos! (Como nunca li Ricardo, deixo-o de fora). [...] No que consistem as descrições do ciclo de crédito apresentadas por Marshall nos seus Principles p. 709-11 e em $\mathrm{M}$ (oney) $\mathrm{C}$ (redit) and C(ommerce) p. 249-51 do que estudos sobre as flutuações na "demanda efetiva"? [...] O que é toda a parte monetária de Industrial Fluctuations e da Theory of Unemployment de Pigou senão um estudo dos movimentos da "demanda efetiva?" (ROBERTSON apud MOGGRIDGE, 1987, p. 504-505).

Apesar da extensa correspondência recíproca, quase nada da contribuição de Robertson encontrou ressonância na Teoria geral. Insatisfeito com a impermeabilidade do colega, Keynes decidiu encerrar os contatos antes da conclusão do livro e, na própria obra, dedicar um capítulo crítico ao conceito de poupança. Isso por duas razões. Primeiro, porque sua nova teoria já não mais admitia discrepâncias entre poupança e investimento, dado que a ação do multiplicador, via variações no nível de renda, garantiria a igualdade entre ambas as variáveis, independentemente do nível da taxa de juros. Além do mais, a teoria dos ciclos do Robertson pareceu-lhe cada vez mais inaceitável pela inoperância que atribuía à ação das autoridades na promoção do pleno-emprego em condições de capacidade ociosa e de homens parados durante a recessão.

No entendimento de Keynes, a expansão dos investimentos em um quadro de desemprego ocasionaria acréscimo na renda monetária, cabendo ao público decidir livremente o montante de poupança correspondente. $\mathrm{O}$ resultado desse processo surgiria na forma de uma quantia adicional de poupança comensurável com o investimento original e que se configuraria tão legítima e voluntária quanto qualquer outro tipo de "privação" (lacking) idealizada por Robertson. Ademais, nesse contexto, assinalou Keynes, ocorreria sempre certa majoração dos preços por conta da elevação dos custos decorrente da produtividade marginal decrescente, de modo que resultaria inviável diferenciar a poupança voluntária daquela realizada de modo forçado. A definição talvez fizesse sentido em uma situação de pleno- emprego, explica Keynes, mas tendo em vista a dificuldade da economia em atingir tal condição devido à insuficiência dos investimentos, seria mais conveniente falar-se de fato em uma deficiência forçada de poupança (KEYNES, 1996, p. 81-85): 
A ideia de que a criação de crédito pelo sistema bancário permite realizar investimentos, aos quais "nenhuma poupança genuína" corresponde, resulta, unicamente, de se isolar uma das consequências do aumento do crédito bancário, com a exclusão das demais. Se a concessão de um crédito adicional a créditos já existentes permite ao empresário efetuar uma adição ao seu investimento corrente, que de outro modo não poderia ocorrer, as rendas aumentarão necessariamente e numa proporção que, em geral, excederá a do investimento suplementar. Além disso, salvo em caso de pleno emprego, tanto a renda real como a monetária serão acrescidas. O público exercerá "uma livre escolha" das proporções em que dividirá o seu acréscimo de rendas entre poupança e dispêndio (KEYNES, 1996, p. 107).

Quanto à teoria dos ciclos propriamente dita, Keynes atribui o fenômeno à volatilidade peculiar da eficiência marginal do capital, intensificada pela ação de outras variáveis fundamentais no comportamento da demanda efetiva. Após uma etapa de forte inversão produtiva, aqueles bens de capital mais abundantes sofreriam maior retração na sua rentabilidade prospectiva, e a consequente queda no investimento poderia ser agravada pelo aumento da taxa de juros decorrente do acréscimo na preferência pela liquidez. Durante a fase recessiva, a longevidade dos bens de capital, como indicara Robertson, aqui, com a concordância de Keynes, representaria um obstáculo à recuperação mais rápida dos investimentos em vista do intervalo requerido à depreciação plena do capital fixo. Em paralelo, a acumulação indesejada de estoques trabalharia para retardar a retomada do crescimento até que voltassem ao seu nível normal. Ainda, o declínio no valor dos títulos públicos e privados exerceria certo efeito riqueza sobre os detentores de tais ativos, que provavelmente reduziriam o seu consumo ao longo do período de retração econômica.

A noção de sobreinvestimento, tal como advogada por Robertson e outros autores continentais, poderia ser concebida, conforme Keynes, unicamente no estado de pleno-emprego, quando o volume total das inversões se mostrasse excessivo. Nesse caso, entretanto, configurar-se-ia impossível apontar os investimentos redundantes, sendo provável que uma elevação nos juros visando conter a fase expansiva afetasse mais diretamente os investimentos úteis. A política recomendável, em vez da austeridade monetária apregoada por muitos economistas da época, envolveria alguma medida de regulação pública dos investimentos, aliada à contenção dos reajustes na taxa de juros, bem como ao reforço na propensão a consumir de forma a manter a economia operando próxima à sua plena capacidade (KEYNES, 1996, p. 293-307):

Assim, o remédio para o auge da expansão não é a alta, mas a baixa da taxa de juros! Pois aquela pode fazer perdurar o chamado auge da expansão. O verdadeiro remédio para o ciclo econômico não consiste em evitar o auge das expansões e em manter assim uma semidepressão 
permanente, mas em abolir as depressões e manter deste modo permanentemente em um quasi-boom! (KEYNES, 1996 , p. 299).

Após a Teoria geral, Keynes envolveu-se em uma discussão relacionada ao conteúdo do livro The trade cycle, de Roy Harrod, e travada em correspondência entre ambos nos meses de março e abril de 1937 (MOGGRIDGE, 1973, p. 150179). Harrod pretendia analisar a dinâmica da economia por meio da interação entre o multiplicador e o acelerador, este último definido como a razão entre as variações no consumo e as variações no investimento, por ele chamado de "relação" e similar ao conceito utilizado anteriormente por Robertson. Keynes objetou a Harrod que a maior dificuldade de tal proposta residia na hipótese de estabilidade das duas variáveis indicadas, porquanto a ação dos preços e da psicologia dos indivíduos durante o ciclo econômico faria por alterar os seus respectivos valores. Assim, a "relação", particularmente no tocante ao consumo, sofreria alterações decorrentes das modificações nos preços de acordo com as leis da oferta e da procura. Preços atrativos induziriam a aquisição daqueles bens produzidos por capital mais abundante, enquanto preços mais caros motivariam investimentos onde eles se fizessem mais prementes. Além disso, do ponto de vista da evolução temporal da economia em condições estáveis, o multiplicador tenderia a se reduzir à medida que declinasse a propensão marginal a consumir, de modo que a taxa de juros precisaria diminuir para estimular um maior investimento, aumentando assim a magnitude da "relação" de Harrod. De qualquer sorte, Keynes mostrou-se relutante em aceitar qualquer tipo de conexão estável entre as variáveis agregadas da economia em vista da precariedade característica da eficiência marginal do capital. Nos seus próprios termos:

De fato, porém, a taxa de investimento não depende do consumo corrente, mas das expectativas (embora estas últimas, é claro, possam ser indevidamente influenciadas pelo consumo atual). Logo, a menos que as expectativas possuam caráter constante, é de se esperar modificações de curto-prazo na relação. [...] O sistema, por conseguinte, tem diversos graus de liberdade. Pode-se verificar, por exemplo, (a) crescimento estável do consumo e do investimento com expectativas instáveis compensadas por uma taxa de juros variável, ou (b) crescimento estável do consumo e crescimento instável do investimento compensado por uma relação e um multiplicador instáveis (KEYNES apud MOGGRIDGE, 1973, p. 172).

\section{Considerações Finais}

Robertson, apesar de sua fidelidade aos ensinamentos de Marshall, introduziu elementos analíticos originais na concepção de Cambridge sobre as flutuações econômicas, inspirado, como visto, nas contribuições de Tugan-Baranovsky, Spiethoff e Aftalion. Primeiramente, sua inclinação a enfatizar os efeitos da indivisibi- 
lidade e longevidade dos bens de capital, bem como das inovações e flutuações agrícolas sobre o investimento agregado refletia claramente as influências mencionadas. Além disso, na percepção de Robertson, as etapas de prosperidade e declínio da acumulação de capital seriam inevitáveis em um sistema regido pelo mercado, no qual as decisões de investimento se realizassem de forma individual e desprovidas de coordenação. Robertson acreditava que os períodos de expansão em ritmo acelerado deveriam ser aceitos com naturalidade por refletirem forças econômicas reais, como uma elevação da demanda por bens de consumo, o surgimento de novos instrumentos de produção, ou mesmo, flutuações nas colheitas, perante as quais a manipulação dos gastos públicos ou da oferta monetária revelar-se-ia inócua. Daí sua designação de "flutuações apropriadas" para eventos dessa natureza. De outra parte, facilidades ou restrições no crédito somente fariam por intensificar a amplitude dos movimentos cíclicos, mediante as diversas formas de poupanças forçadas ou induzidas, as quais deveriam, de fato, ser evitadas de modo a atenuar ao máximo o que entendia como "flutuações inapropriadas".

Importa destacar ainda que, mesmo admitindo larga diversidade nas formas possíveis de poupança, a análise monetária de Robertson permaneceu subordinada à concepção marshalliana mais geral sobre a determinação das taxas de juros. À medida que Keynes apartou-se progressivamente dessa forma de compreensão dos fenômenos monetários nos anos de 1930, sua ruptura com Robertson tornou-se inevitável. Especificamente no tocante à teoria da poupança forçada, Keynes, antes simpático à ideia, viria a se tornar um de seus mais severos críticos. A divisão analítica entre fatores reais e monetários no estudo da instabilidade da economia, tão característica de Marshall, Pigou e Robertson, converteu-se, para Keynes, em impedimento a uma compreensão mais profunda das limitações de uma economia madura, porquanto a poupança, uma vez aceita como induzida pelo próprio investimento via multiplicador, já não mais poderia ser entendida como fator determinante da taxa de juros, fosse bancária ou natural. A partir dessa perspectiva, Keynes, diferentemente de Robertson, e levando a tradição de Cambridge ao seu extremo, descortinou amplo campo de intervenção das autoridades na economia por meio de políticas voltadas à estabilização do investimento e à promoção do consumo como forma de promover a plena utilização dos recursos humanos e materiais da sociedade.

\section{Referências}

AFTALION, A. Les crises périodiques de surproduction. Paris: Marcel Rivière, 1913.

ARTHMAR, R. A economia clássica contra os fatos ou Sismondi entre os ricardianos. Economia e Sociedade, v.18, n.2, p. 261-285, ago. 2009. 
BACKHOUSE, R.E.; NISHIZAWA, T. Introduction: towards a reinterpretation of the history of welfare economics. In: BACKHOUSE, R.E.; NISHIZAWA, T. (ed.). No wealth but life: welfare economics and the welfare state in Britain, 1880-1945. Cambridge: Cambridge University Press, 2010.

BARNETT, V. Tugan-Baranovsky as a pioneer of trade cycle analysis. Journal of the History of Economic Thought, v.23, n.4, p.443-66, 2001.

BAUMOL, W. Say's (at least) eight laws or what Say and James Mill may really have meant. Economica, New Series, v. 44, n. 174, p.145-61, May 1977.

BIGG, R. J. Cambridge and the monetary theory of production: the collapse of Marshallian macroeconomics. New York: St. Martin's, 1990.

BRIDEL, P. Cambridge monetary thought: the development of saving-investment analysis from Marshall to Keynes. New York: St. Martin's, 1987.

DIEBOLT, C. Le cycle économique chez Arthur Spiethoff. Revue d'Économie Politique, v. 117, n. 4, p. 631-641, 2007.

DEUTSCHER, P. Hawtrey and Robertson: real and monetary roots of English macroeconomics in the twentieth century. In: HENINGS, K.; SAMUELS, W. (ed.). Neoclassical economic theory, 1870 to 1930. London: Kluwer Academics, p. 59-87, 1990.

FLETCHER, G. Dennis Robertson. Basingstoke: Palgrave Macmillan, 2008.

FORGET, E. John Stuart Mill's business cycles. History of Political Economy, v. 22, n. 4, 629$642,1990$.

HABERLER, G. Some reflections on the present situation of business cycles theory. The Review of Economics and Statistics, v.18, n.1, p. 1-7, 1936.

HABERLER, G. Prosperity and depression: a theoretical analysis of cyclical movements. 3rd ed. New York: United Nations, 1946.

HANSEN, A. Business cycles and national income. New York: Norton, 1964.

HAYEK, F. A note on the development of the doctrine of 'forced saving'. The Quarterly Journal of Economics, v.47, n. 1, p. 123-133, Nov. 1932.

HYNDMAN, H. M. Commercial crisis of the nineteenth century. New York: Augustus M. Kelley, 1903.

KATES, S. Say's law and the Keynesian revolution. Cheltenham: E. Elgar, 1998.

KEYNES, J. M. A teoria geral do emprego, do juro e da Moeda. São Paulo: Nova Cultural, 1996.

LAIDLER, D. The golden age of the quantity theory. Princeton: Princeton University Press, 1991.

LAIDLER, D. Fabricating the Keynesian revolution: studies of the inter-war literature on money, the cycle, and unemployment. Cambridge: Cambridge University Press, 1999. 
MARSHALL, A.; MARSHALL, M.P. The economics of industry. Bristol: Thoemmes Press, 1994.

MARSHALL, A. Principles of economics. 8th ed. London: Macmillan, 1920.

MARSHALL, A. Money, credit and commerce. London: Macmillan, 1923.

MILL, J.S. Principles of political economy: books III-V and appendices. In: ROBSON, J.M. (ed.). Collected works of John Stuart Mill. Toronto: University of Toronto Press, 1965. v. 3.

MILIOS, J.; SOTIROPOULOS, D. Tugan-Baranowsky and effective demand. Science and Society, v. 71, n. 2, p. 227-242, 2007.

MITCHELL, W.C. Business cycles. Berkeley: University of California Press, 1913.

MOGGRIDGE, D. (ed.). The collected writings of John Maynard Keynes: the general theory and after: part II, defense and development. London: Macmillan, 1973. v. 14.

MOGGRIDGE, D. (ed.). The collected writings of John Maynard Keynes: the general theory and after: part I, preparation. London: Macmillan, 1987. v. 13.

PATINKIN, D. Anticipations of the general theory? And other essays on Keynes. Chicago: The University of Chicago Press, 1982.

PIGOU, A.C. The economics of welfare. London: Macmillan, 1920.

PRESLEY, J.R. Robertsonian economics: an examination of the work of Sir D.H. Robertson on industrial fluctuation. New York: Holmes $\mathcal{J}$ Meier, 1979.

ROBERTSON, D.H. A study of industrial fluctuation: an enquiry into the character and causes of the so-called cyclical movements of trade. London: The London School of Economics and Political Science, 1948.

ROBERTSON, D.H. A moeda. Rio de Janeiro: Zahar, 1960.

ROBERTSON, D.H. Banking policy and the price level: an essay in the theory of the trade cycle. London: P.S. King E Son, 1932.

ROBERTSON, D.H. Industrial fluctuation and the natural rate of interest. The Economic Journal, v.44, n. 176, p. 650-665, Dec. 1934.

TUGAN-BARANOVSKY, M. Les crises industrielles en Anglaterre. Paris: M. Giard E É. Brière, 1913.

WOLFE, J.N. Marshall and the trade cycle. Oxford Economic Papers, New Series, v. 8, n.1, 90-101, Feb. 1956.

Recebido em: 11/08/2017.

Aceito em: 09/03/2018.

(cc) BY 